\title{
A Model For Design Auto Instrumentation To Appeal To Young Male Customers
}

\author{
Koichiro Yazaki, Aoyama Gakuin University, Japan \\ Haruki Tanitsu, Aoyama Gakuin University, Japan \\ Hiroki Hayashi, Aoyama Gakuin University, Japan \\ Kakuro Amasaka, Aoyama Gakuin University, Japan
}

\begin{abstract}
This paper applies statistical science to create a model for auto instrumentation, an aspect of vehicle design that has a powerful effect on young male customers. The authors develop an instrumentation design that will appeal to the target users to verify the effectiveness of an Auto Instrumentation Designing Approach Model.
\end{abstract}

Keywords: Auto Instrumentation; Statistical Science; Designing Approach Model

\section{INTRODUCTION}

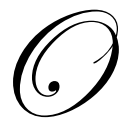

ne of the most critical issues facing Japanese industries in the $21^{\text {st }}$ century is how to create appealing products and reform the product design process. Taking new product development in the auto industry, as an example, accurately grasping increasingly diverse customer preferences requires the creation of a new design approach model that can scientifically assess those preferences. As an application for this research, we apply statistical science to create a model for auto instrumentation, an aspect of vehicle design that has a powerful effect on young male customers. Factors that young men consider important in terms of image are listed, including sporty, sharp, fresh, and youthful. Next, design components that need to be incorporated into the instrumentation design are identified, including the number of gauges, gauge color and shape, the shape of the gauge frames, the color of gauge needles, and size and color of the measurement gradations. Next, this information is used to design preferences of young men, generating a formula for causal relationship between customer image preferences and key design elements.

The formula is used to clarify the design elements that make up the instrumentation design and layout preferred by target customers who prioritize design. These design parameters are then used to create CAD data showing a design that will appeal to them. Finally, we develop an instrumentation design that will appeal to the target users to verify the effectiveness of their model.

\section{BACKGROUND}

The product planning process at automakers starts with market surveys where user studies, technical information, market share of current products, and a variety of other information are collected and analyzed in order to determine the kinds of designs that are popular. Target users, performance specifications, price and other basic requirements for the new vehicle are determined based on the collected information and sent to the design department of an auto instrumentation manufacturer.

A great deal of research has already been conducted on assessing customer preferences in terms of the exterior design of vehicles (Amasaka, 2006; Amasaka, 2007; Ando et al., 2008; Okabe et al., 2006; Ando et al., 2010; Takebuchi et al., 2010). Research has also been done on aspects of the interior - particularly the visibility, recognizability display technology, and other aspects of vehicle instrumentation - but so far, none has been presented on the subjective impression of instrumentation design (Shibata et al., 2003; Yamamoto et al., 2004; Shimada and Shinomori, 2006). 
During the initial stages of instrumentation design, vehicle instrumentation design departments use experiential knowledge and other strategies to interpret the vehicle concept presented by the automaker and set targets that will allow them to carry out their design work efficiently. For example, an automaker may propose a "friendly, luxurious design" or a design that promises "reasonable performance without conveying a rigid adherence to drab practicality."

The instrumentation manufacturer works with the automaker to translate the concept into a concrete design, but because this design process is often inexplicit, the final instrumentation design is often far removed from the one presented in the competition. In light of this situation, we use Customer Science backed by statistics to create an Auto Instrumentation Designing Approach Model based on research applications of the Automobile Exterior Design Approach Model to profile design, shape, and design color.

\section{THE IMPORTANCE OF DESIGNING AUTO INSTRUMENTATION THAT MATCHES CUSTOMER PREFERENCES}

Drivers must be able to see the instrument panel through the round steering wheel while they are operating the vehicle, and designing auto instrumentation that matches customer preferences within this limited visible space is no easy task.

Drivers spend a large percentage of their time looking at the auto instrumentation, or gauges, when the front of the vehicle is in their field of vision. Studies that used the eye-mark recording system to measure the amount of time drivers spend looking at the gauges while driving have revealed that the figure is as high as $22 \%$. Instrumentation design must achieve high visibility at high speed (functional quality) as well as offer an appealing design (subjective quality). However, as explained earlier, the current instrumentation design approach used to go from a design concept to a drawing and relied heavily on implicit experiential knowledge of designers at the automaker and the instrumentation manufacturer. In addition, our research has revealed that both designer groups often fail to objectively pinpoint customer preferences, and instead design for their personal conception of the target user via a process that is heavily subjective and experience-based. What these designers are looking for is an instrumentation design process that uses Customer Science to objectively grasp customer preferences (Amasaka et al., 1999; Amasaka, 2005).

\section{PROPOSING THE AUTO INSTRUMENTATION DESIGN APPROACH MODEL}

To meet the need for a way to visualize customer preferences and create gauge designs that match them, we put together the Auto Instrumentation Designing Approach Model shown in Figure 1. Steps 1-5 of the model will be explained using a concrete example.

\section{Selection of A Preference Group from among Target Users}

Step 1 of the model is selecting a preference group from among target users. In this step, a preference survey was conducted in order to clarify the preferences of young males. Survey items consisted of questions about instrumentation (including the kinds of gauges that participants preferred and the parts of the gauges they tended to focus on) and questions about automobiles, such as vehicle interests, values, and preferences and vehicle purchase behavior. Participants were men in their late teens and early 20 s and 40 responses were received. For the questions on instrumentation design preferences, 28 subjective words related to design were selected from prior research and interviews (Figure 2) (Ando et al., 2008; Takebuchi et al., 2010). Participants were then asked to evaluate how closely each word described their preferences using a seven-point scale.

A preference group of target users was then selected based on the results of the preference survey. First, data from the seven-point scale questions on instrumentation design preferences were used to conduct a cluster analysis in order to define preference groups based on differences among target users in the priority they placed on the subjective words. As indicated in Figure 3, four separate preference groups were identified - price-conscious users, users uninterested in purchasing, function-conscious users, and design-conscious users. Users in the designconscious group showed particularly strong preferences toward vehicles and it was clear that they had the most interest in instrumentation. We thus decided to create an instrumentation design that targeted the design-conscious 
group. A principle component analysis was then conducted in order to clarify the instrumentation design preferences of each group, which was done successfully. As a result of these analyses, six preference elements were identified for the design-conscious group - sporty, sharp, fresh, youthful, intricate, and visually striking. We then identified instrumentation design factors in order to create an instrumentation design that reflected these elements.

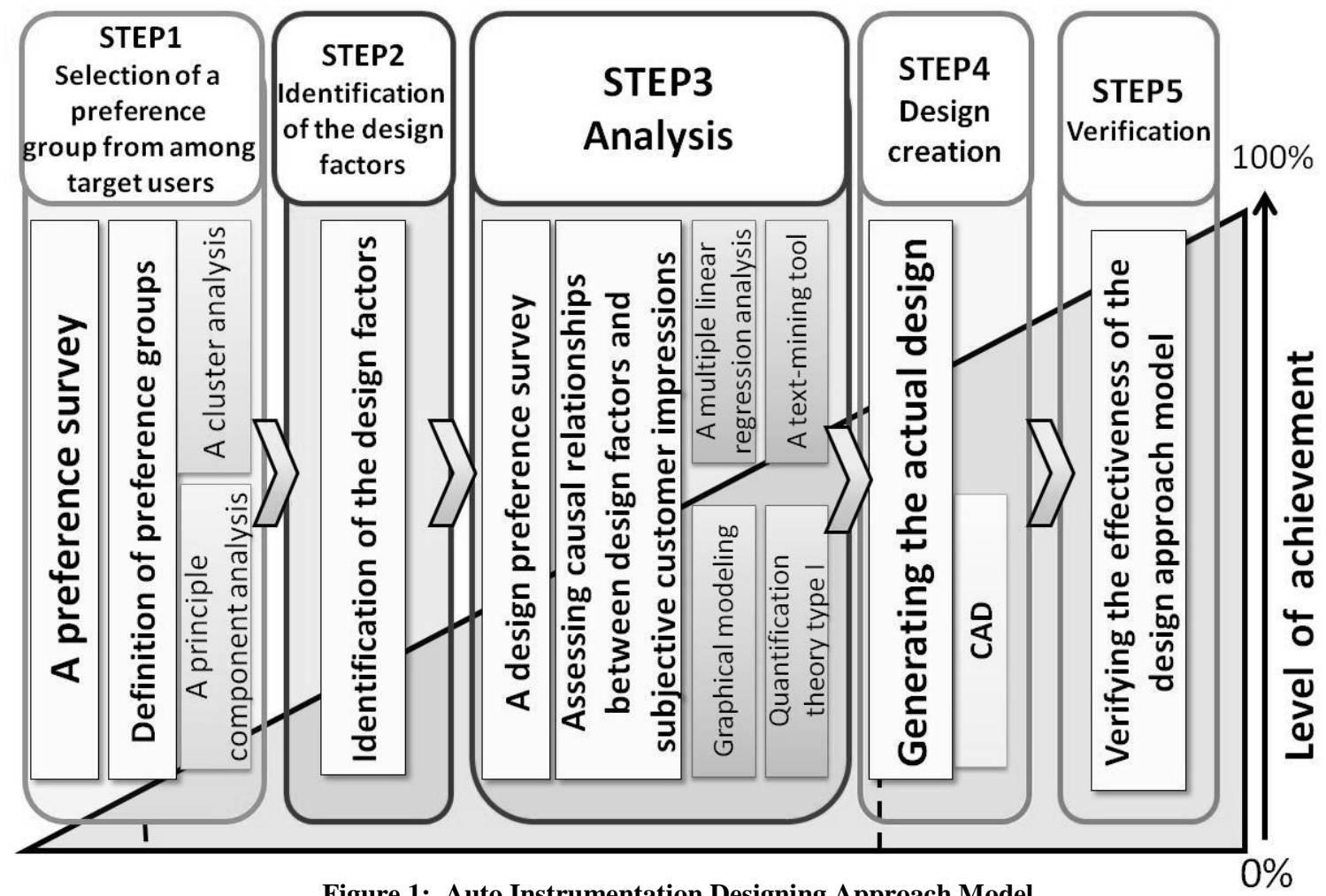

Figure 1: Auto Instrumentation Designing Approach Model

Instrumentation design preferences, 28 subjective words

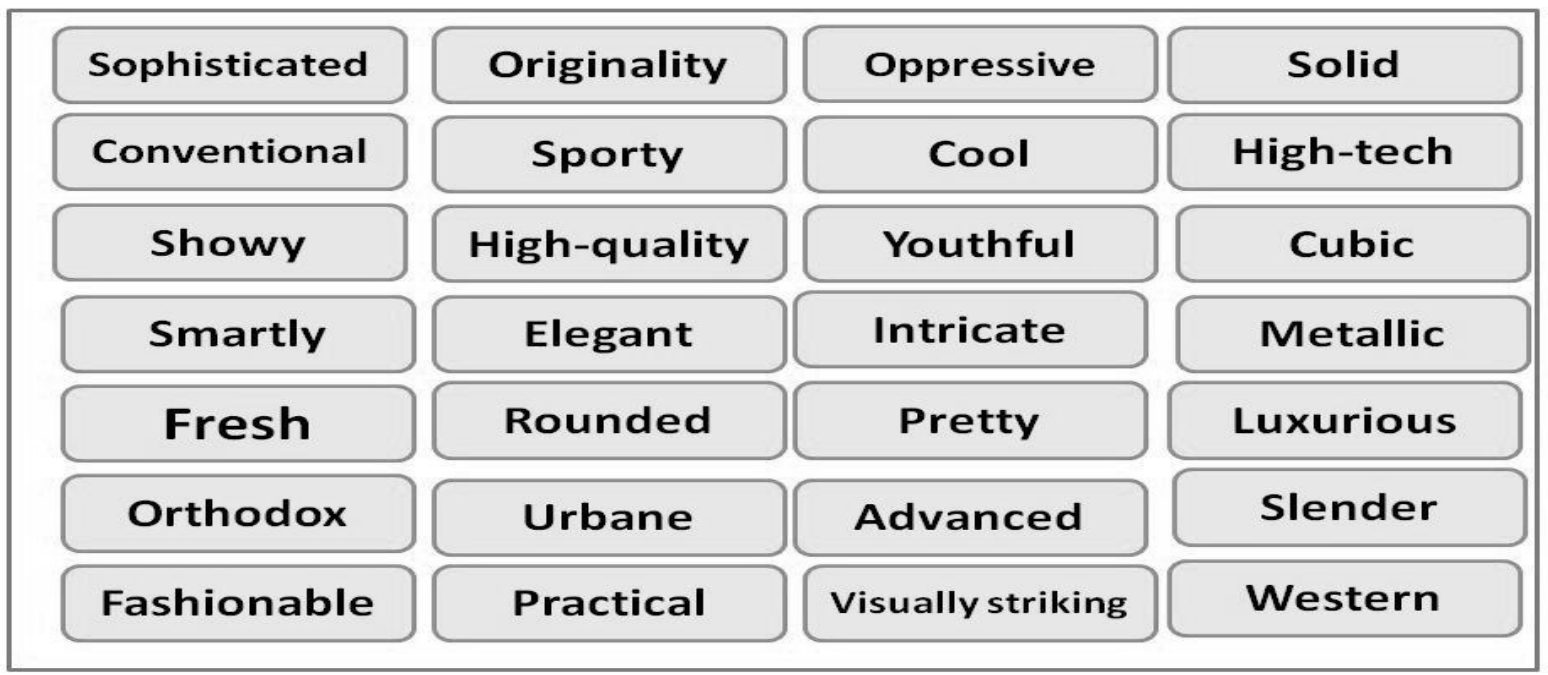

Figure 2: Selected Subjective Words 


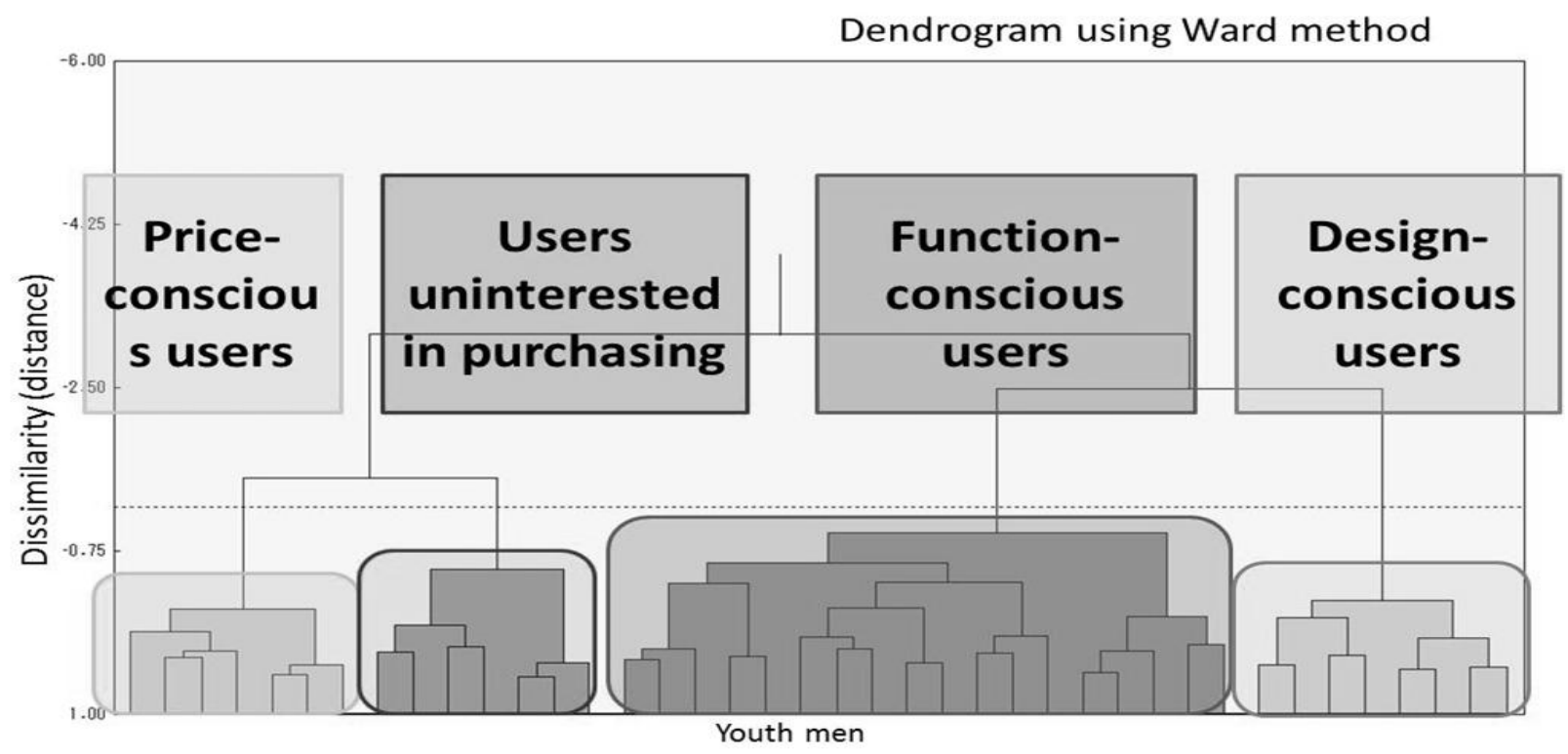

Figure 3: Preference Groups Identified via Cluster Analysis

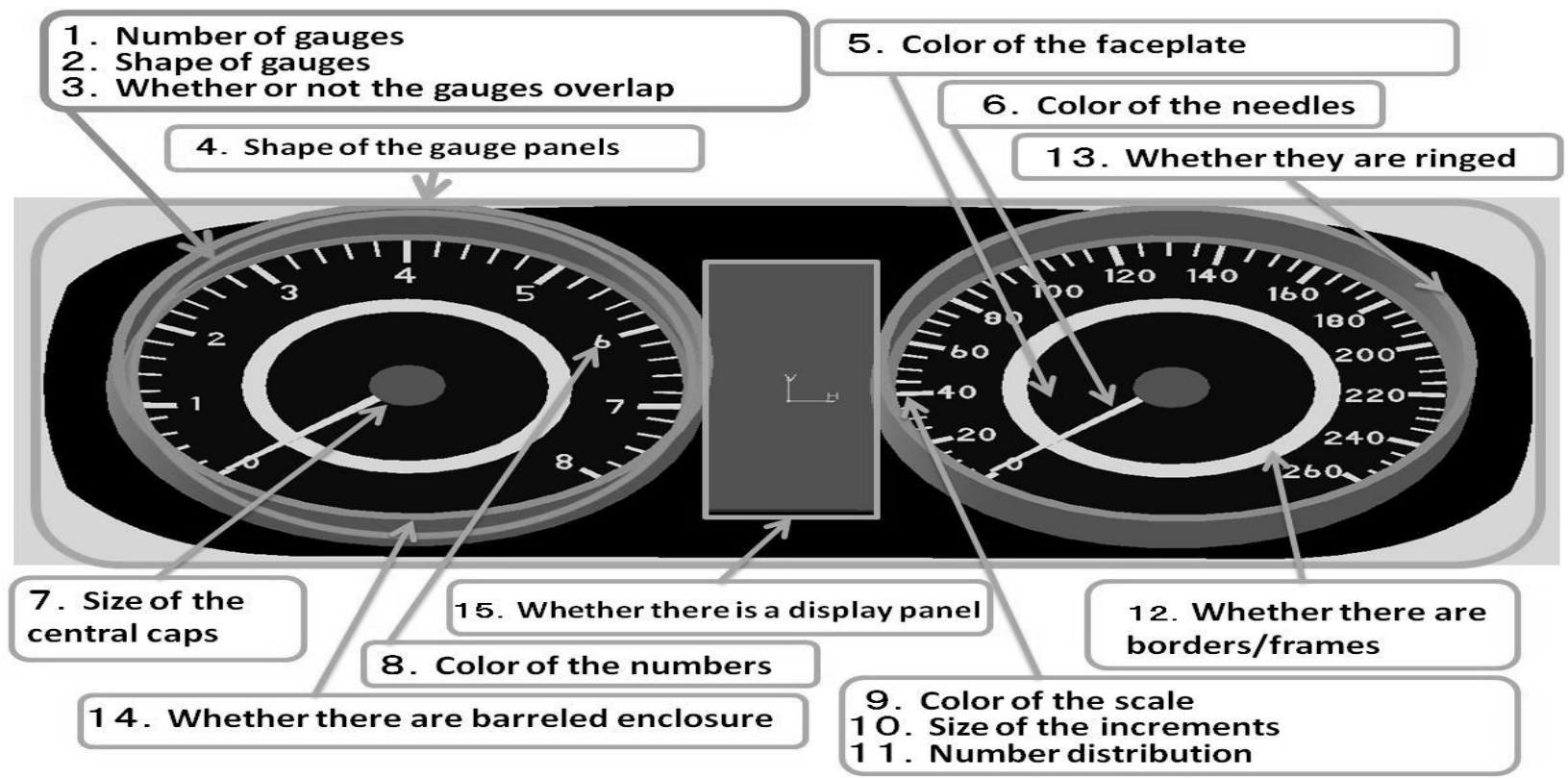

Figure 4: Design Factors

Identification of the Design Factors

In step 2, we conducted a survey of instrumentation currently on the market, a survey to see what part of the gauges customers tend to focus on, and interviews at companies with the aim of identifying the design factors that make up instrumentation design. A total of 15 design factors were identified - number and shape of gauges, whether or not the gauges overlap, shape of the gauge panels, color of the faceplate, color of the needles, size of the central caps, color of the numbers, color of the scale and size of the increments, number distribution, whether there are borders/frames, whether they are ringed, whether there is a barreled enclosure, and whether there is a display panel (Figure 4). These design factors were further broken down into a total of 49 parameters (Table 1). The 
identified design factors and associated parameters were then used to generate data on and classify instrumentation from 36 vehicle models currently on the market (Table 2).

The procedures in steps 1 and 2 allowed us to generate an instrumentation design that captures the preferences of the design-conscious target group. In step 3, each part of the instrumentation design was analyzed to determine what kind of subjective impression it would have on customers.

Table 1: Design Factors and Parameters

\begin{tabular}{|c|c|c|c|c|c|c|c|}
\hline \multirow{6}{*}{1} & \multirow{6}{*}{ Number of gauges } & a1 & \multirow{2}{*}{$\begin{array}{l}1 \\
2 \\
\end{array}$} & \multirow{4}{*}{8} & \multirow{4}{*}{ Color of the numbers } & h1 1 & White \\
\hline & & a2 & & & & h2 & Orange \\
\hline & & a3 & 3 & & & h3 & Blue \\
\hline & & a4 & 4.1 & & & h4 & Black \\
\hline & & a5 & 4.2 & \multirow{4}{*}{9} & \multirow{4}{*}{ Color of the scale } & i1 & White \\
\hline & & a6 & 4.3 & & & $i 2$ & Red \\
\hline \multirow{3}{*}{2} & \multirow{3}{*}{ Shape of gauges } & b1 & Type 1 & & & i3 & Blue \\
\hline & & b2 & Type 2 & & & i4 & Black \\
\hline & & b3 & Type 3 & \multirow{2}{*}{10} & \multirow{2}{*}{ Size of the increments } & j1 & Big \\
\hline \multirow{2}{*}{3} & \multirow{2}{*}{ Whether or not the gauges overlap } & c1 & Existence & & & j2 & Small \\
\hline & & $\mathrm{c2}$ & Nothing & \multirow{2}{*}{11} & \multirow{2}{*}{ Number distribution } & k1 & Horizontal \\
\hline \multirow{6}{*}{4} & \multirow{6}{*}{ Shape of the gauge panels } & d1 & Type 1 & & & k2 & Radial \\
\hline & & d2 & Type 2 & \multirow{4}{*}{12} & \multirow{4}{*}{ Whether there are borders/frames } & 11 & Nothing \\
\hline & & d3 & Type 3 & & & 12 & Red \\
\hline & & d4 & Type 4 & & & 13 & Blue \\
\hline & & d5 & Type 5 & & & 14 & White \\
\hline & & d6 & Type 6 & \multirow{3}{*}{13} & \multirow{3}{*}{ Whether they are ringed } & $\mathrm{m} 1$ & Nothing \\
\hline \multirow{2}{*}{5} & \multirow{2}{*}{ Color of the faceplate } & e1 & Black & & & $\mathrm{m} 2$ & Fine \\
\hline & & e2 & White & & & $\mathrm{m} 3$ & Thick \\
\hline \multirow{4}{*}{6} & \multirow{4}{*}{ Color of the needles } & $\mathrm{f1}$ & White & \multirow{2}{*}{14} & \multirow{2}{*}{ Whether there are barreled enclosure } & n1 & Nothing \\
\hline & & $\mathrm{f2}$ & Red & & & n2 & Existence \\
\hline & & f3 & Blue & \multirow{2}{*}{15} & \multirow{2}{*}{ Whether there is a display panel } & 01 & Nothing \\
\hline & & $\mathrm{f4}$ & Silver & & & 02 & Existence \\
\hline \multirow{3}{*}{7} & \multirow{3}{*}{ Size of the central caps } & g1 & Nothig & & & & \\
\hline & & g2 & Small & & & & \\
\hline & & g3 & Big & & & & \\
\hline
\end{tabular}

Table 2: Qualitative Data from the 36 Instrumentation Designs Currently on the Market

\begin{tabular}{|c|c|c|c|c|c|c|c|c|c|c|c|c|c|c|c|}
\hline Sample & 1 & 2 & 3 & 4 & 5 & 6 & 7 & 8 & 9 & $\begin{array}{l}1 \\
0\end{array}$ & $\begin{array}{l}1 \\
1\end{array}$ & $\begin{array}{l}1 \\
2\end{array}$ & $\begin{array}{l}1 \\
3\end{array}$ & $\begin{array}{l}1 \\
4\end{array}$ & $\begin{array}{l}1 \\
5\end{array}$ \\
\hline 3 series & a2 & b1 & c2 & d1 & e 1 & $\mathrm{f1}$ & g2 & h1 & i1 & j1 & $\mathrm{k} 1$ & 11 & $\mathrm{~m} 2$ & n1 & 02 \\
\hline $\begin{array}{l}\text { FAIRLADY } \\
Z\end{array}$ & a3 & b1 & c2 & d5 & e 1 & f2 & g2 & h1 1 & i1 & j2 & k1 & 12 & $\mathrm{~m} 2$ & n2 & 01 \\
\hline ALPHARD & a5 & b2 & c2 & d4 & e 1 & f3 & g2 & h1 & i1 & j1 & $\mathrm{k} 2$ & 11 & m3 & $n 1$ & 01 \\
\hline S3 & a5 & b1 & c2 & d2 & e 1 & $\mathrm{f1}$ & g2 & h1 & i1 & j2 & $\mathrm{k} 1$ & 11 & $\mathrm{~m} 2$ & n1 & 01 \\
\hline AURIS & $a 6$ & b2 & c2 & d5 & e 1 & $\mathrm{f2}$ & g2 & h2 & $i 2$ & $\mathrm{j} 2$ & $\mathrm{k} 2$ & 11 & $\mathrm{~m} 3$ & n1 & 01 \\
\hline fit & a3 & b2 & c2 & d2 & e 1 & $\mathrm{f2}$ & g3 & h2 & i1 & $\mathrm{j} 2$ & k1 & 14 & $\mathrm{~m} 3$ & $n 2$ & 01 \\
\hline $\begin{array}{l}\text { CROWN } \\
\text { HYBRID }\end{array}$ & a2 & b2 & c2 & d2 & e 1 & $f 1$ & g1 & h1 & i1 & j2 & k2 & 13 & $\mathrm{~m} 1$ & n 1 & 01 \\
\hline 70a. & a & b1 & a.2 & d2 & e 1 & f2 & 2 & a & 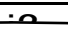 & $1: 2$ & $k 1$ & 11 & $\mathrm{~m} 2$ & $n 1$ & 01 \\
\hline$\triangle 1 C L C L$ & av & $10=$ & & & & & & साT & TT & ए< & & & & & \\
\hline FUGA & a6 & b1 & c2 & d5 & e 1 & $f 1$ & g2 & h1 & i1 & $\mathrm{j} 2$ & $\mathrm{k} 1$ & 13 & m3 & $n 1$ & 01 \\
\hline ISIS & a3 & b2 & c1 & d4 & e 1 & $\mathrm{f1}$ & g2 & h1 & i1 & $\mathrm{j} 2$ & k1 & 13 & $\mathrm{~m} 2$ & $n 1$ & 01 \\
\hline $\begin{array}{l}\text { LAND } \\
\text { CRUISER }\end{array}$ & a2 & b1 & c2 & d2 & e 1 & $f 1$ & g2 & h3 & i3 & j 1 & k 1 & 11 & $\mathrm{~m} 3$ & n2 & 01 \\
\hline Porte & a2 & b3 & c1 & d6 & e 1 & f2 & g2 & h1 & i1 & j2 & $\mathrm{k} 2$ & 12 & $\mathrm{~m} 1$ & n1 & 01 \\
\hline $\mathrm{RX}$ & $a 6$ & b2 & c2 2 & d2 & e 1 & $f 4$ & g2 & h1 & i1 & j2 & k1 & 13 & $\mathrm{~m} 2$ & $n 1$ & 02 \\
\hline $\mathrm{S}$ & a6 & b2 & c2 & d2 & e 1 & $\mathrm{f1}$ & g2 & h1 & i1 & $\mathrm{j} 2$ & $\mathrm{k} 1$ & 13 & $\mathrm{~m} 1$ & n1 & 01 \\
\hline Ractis & a2 & b2 & c2 & d1 & e 1 & f2 & g2 & h1 & i1 & j1 & $\mathrm{k} 2$ & 12 & $\mathrm{~m} 1$ & $n 1$ & 02 \\
\hline RAUM & a3 & b3 & c1 & d6 & e2 & f2 & g3 & h4 & i4 & j2 & $\mathrm{k} 1$ & 11 & $\mathrm{~m} 2$ & $n 1$ & 01 \\
\hline RUMION & a4 & b1 & c1 1 & d3 & e 1 & f2 & g2 & h1 & i1 & j1 & k1 & 11 & $\mathrm{~m} 2$ & $n 1$ & 01 \\
\hline RUSH & a3 & b2 & c2 & d5 & e 1 & $\mathrm{f4}$ & g2 & h1 & i1 & i2 & $\mathrm{k} 1$ & 11 & $\mathrm{~m} 2$ & n1 & 01 \\
\hline
\end{tabular}




\section{Analysis}

\section{Assessing The Level of Impact among Subjective Words}

In step 3, an analysis was conducted in order to qualify the instrumentation design using individual subjective responses and design factors. Before beginning, the design-conscious group was given another design preference survey in order to assess the degree to which instrumentation design factors affected their subjective impressions. Participants were asked whether they liked the instrumentation on each of the 36 models used in step 2 and asked to evaluate how well six subjective words applied to the design using a seven-point scale. They were also asked to provide detailed feedback in a free response section. A multiple linear regression analysis was done on the data and graphical modeling was used to find out which of the subjective key words had the greatest impact on the ideal design. In the multiple linear regression analysis, variables were selected using a stepwise variable selection method, with the preference score (whether the participants liked the design) as the objective variable and the scores for the other six subjective words as explanatory variables. As a result of the analysis, "sporty", "sharp", and "youthful" were selected and the requested design was expressed in the following standard partial regression coefficient formula (1).

$\mathrm{Z}^{\prime}=0.298 \mathrm{y}_{1}{ }^{\prime}+0.177 \mathrm{y}_{2}{ }^{\prime}+0.435 \mathrm{y}_{3}{ }^{\prime}$

However, it remained unclear how the subjective words that were not chosen (fresh, intricate, visually striking) affected whether respondents liked the design or not, so graphical modeling was used to find out. The results indicated that the words "sporty", "sharp", and "young" from Figure 5 were directly related to whether respondents visually liked the design, while the three subjective words that were not chosen during the multiple linear regression analysis were related through the other words. This meant that of the six subjective words, "sporty", "sharp", and "youthful" had greater impact; so the study sought to boost the level of these characteristics in order to generate a liking for the instrumentation design among the target customers.

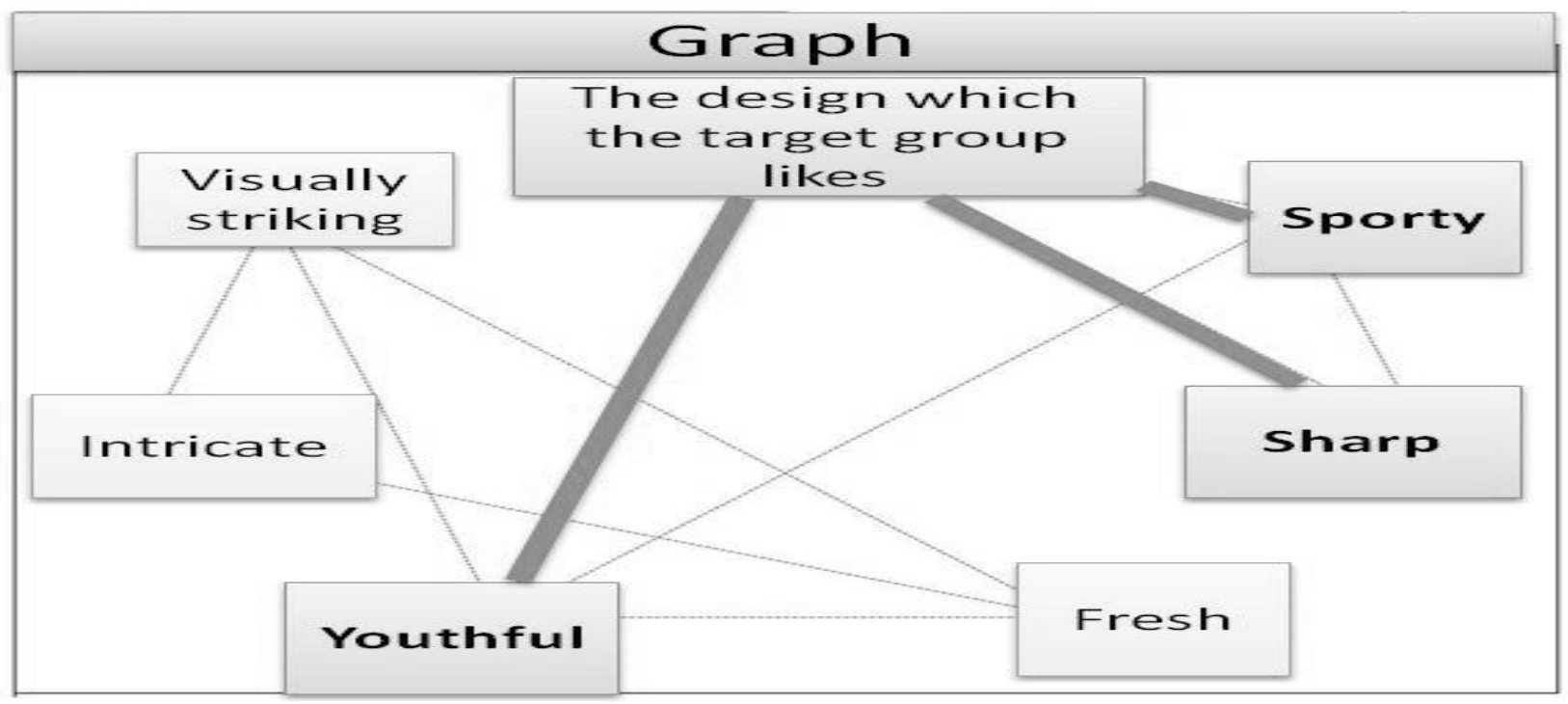

Figure 5: Assessing the Level of Impact among Subjective Words using Graphical Modeling

\section{Assessing Causal Relationships between Design Factors and Subjective Customer Impressions}

Next, a text-mining tool and quantification theory type I were used in order to assess the causal relationships between parametric changes in design factors and subjective customer impressions. The text-mining 
tool revealed word linkages using the free response feedback in the design preference survey and also showed what aspects of the instrumentation conferred the subjective impressions defined by the three primary key words, as well as the positive and negative elements of each (Figure 6).

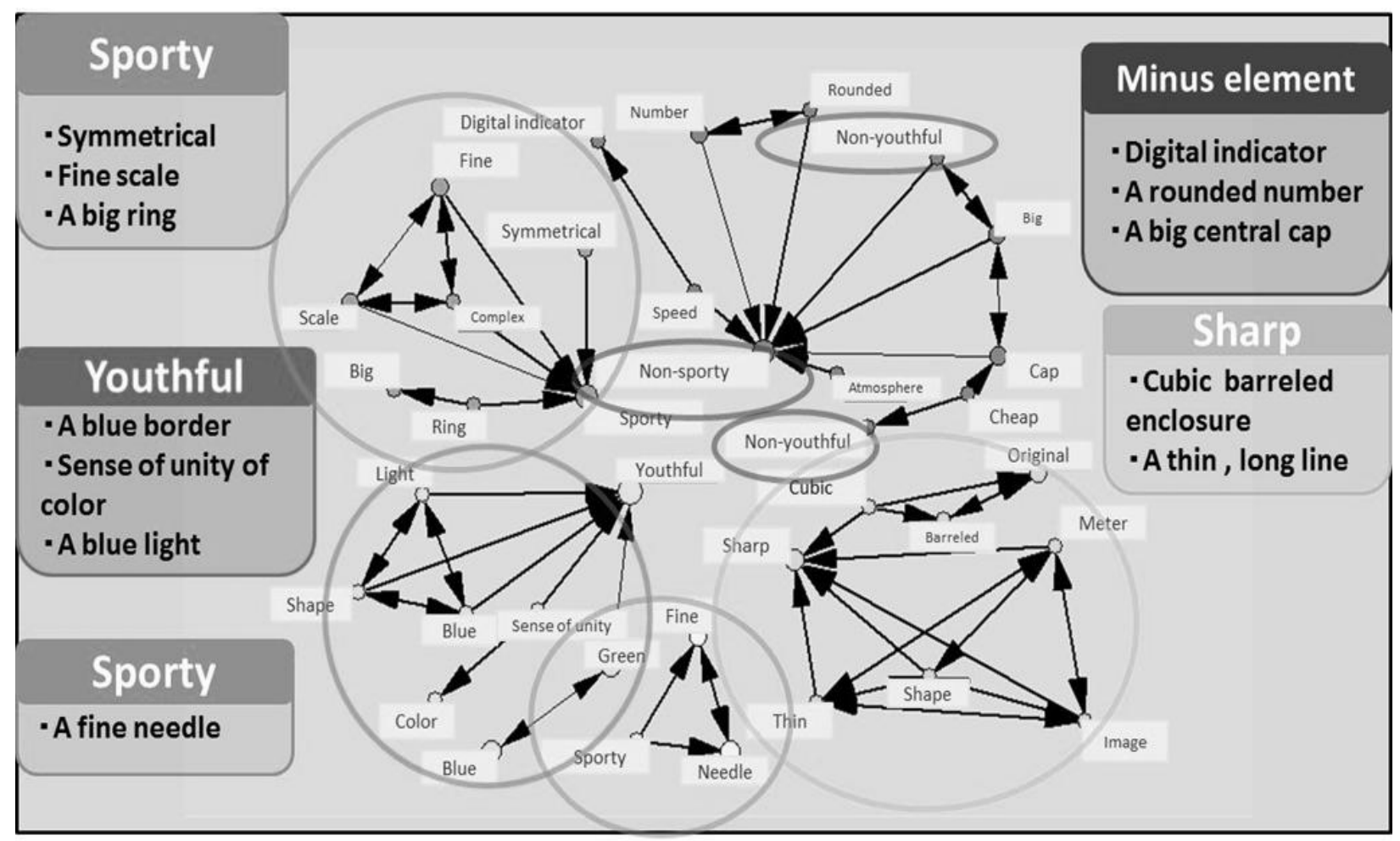

Figure 6: Word Network Text Mining Diagram

Quantification theory type I used the subjective evaluation data from the design preference survey as well as qualitative data from the 36 instrumentation designs currently on the market (Table 2). The scores for "sporty", "sharp", and "youthful" were used as objective variables, while the design factors and qualitative parameter variables were used as explanatory variables. One of the results of the analysis is the weighted path diagram in Figure 7, which shows the standard partial regression coefficients for "sporty." The standard partial regression coefficients in the path diagram that influence the objective variables in a positive direction are marked with a solid arrow and a "+", while those that influence the objective variables in a negative direction are marked with a broken arrow and a "-". Figure 7 thus indicates which of the design factor parameters most powerfully impacts the "sporty" element. Formula (2) mathematically expresses the degree of impact of the design factor parameters on "sporty" using standard partial regression coefficients. A similar analysis was carried out for "sharp" and "youthful", revealing the causal relationships between design factors and subjective customer impressions. The corresponding mathematical formulas are shown in (3) and (4). 


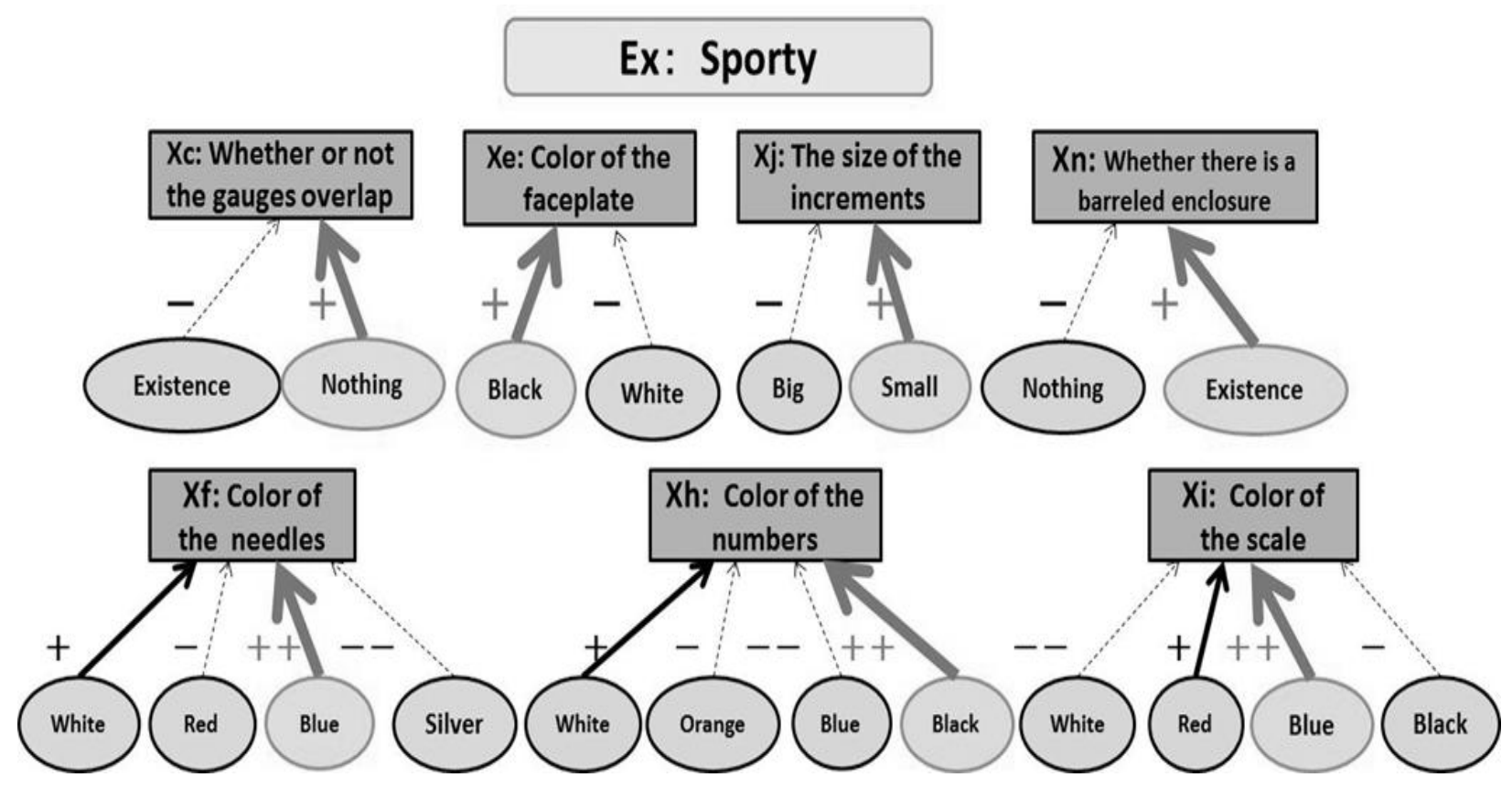

Figure 7: Path Diagram indicating the Relative Impact of Preference Elements and Design

$\mathrm{y}_{1}^{\prime}=(-0.157) \mathrm{x}_{\mathrm{c} 2}+(-0.507) \mathrm{x}_{\mathrm{e} 2}+(-0.214) \mathrm{x}_{\mathrm{f} 2}+(0.125) \mathrm{x}_{\mathrm{f} 3}+(-0.247) \mathrm{x}_{\mathrm{f} 4}+(-0.196) \mathrm{x}_{\mathrm{h} 2}+(-0.226) \mathrm{x}_{\mathrm{h} 3}+(0.211) \mathrm{x}{ }_{\mathrm{h} 4}+$ $(0.203) \mathrm{x}_{\mathrm{i} 2}+(0.299) \mathrm{x}_{\mathrm{i} 3}+(0.161) \mathrm{x}_{\mathrm{i} 4}+(0.178) \mathrm{x}_{\mathrm{j} 2}+(0.239) \mathrm{x}_{\mathrm{n} 2}$

$\mathrm{y}_{2}{ }_{2}=(0.119) \mathrm{x}_{\mathrm{d} 2}+(-0.167) \mathrm{x}_{\mathrm{d} 3}+(0.179) \mathrm{x}_{\mathrm{d} 4}+(0.015) \mathrm{x}_{\mathrm{d} 5}{ }+(-0.027) \mathrm{x}_{\mathrm{d} 6}+(-0.383) \mathrm{x}_{\mathrm{e} 2}+(-0.153) \mathrm{x}{ }_{\mathrm{h} 2}+(-0.075) \mathrm{x}{ }_{\mathrm{h} 3}+$ $(0.215) \mathrm{x}_{\mathrm{h} 4}+(0.101) \mathrm{x}_{\mathrm{n} 2}+(0.134) \mathrm{x}{ }_{\mathrm{o} 1}$

$\mathrm{y}_{3}{ }_{3}=(0.214) \mathrm{x}_{\mathrm{d} 2}+(0.012) \mathrm{x}_{\mathrm{d} 3}+(0.265) \mathrm{x}_{\mathrm{d} 4}+(0.030) \mathrm{x}_{\mathrm{d} 5}+(-0.118) \mathrm{x}_{\mathrm{d} 6}+(-0.367) \mathrm{x}_{\mathrm{e} 2}+(-0.123) \mathrm{x}_{\mathrm{h} 2}+(-0.021) \mathrm{x}{ }_{\mathrm{h} 3}+$ $(0.351) \mathrm{x}_{\mathrm{h} 4}+(0.171) \mathrm{x}{ }_{\mathrm{k} 2}+(0.246) \mathrm{x}{ }_{12}+(0.303) \mathrm{x}{ }_{13}+(0.152) \mathrm{x}_{14}+(0.180) \mathrm{x}{ }_{\mathrm{n} 2}+(0.212) \mathrm{x}{ }_{\mathrm{o} 1}$

The above analysis determined the design factor parameters that would boost the "sporty", "sharp", and "youthful" aspects of instrumentation design. Design factor parameters that contradict each subjective word were not selected in this study, but it is possible that unrelated parameters could have been selected. Therefore, the three formulas derived from the quantification theory type I analysis were substituted for the requested instrumentation formula derived during the multiple linear regression analysis. This allowed the determination of a more unique requested instrumentation design. In step four, this information was used to actually create that design.

\section{Generating the Actual Design}

In step 4, CAD was used to generate the instrumentation design preferred by young males, who were the targets defined in step 3. The ideal instrumentation formula from step 3 was used to generate a design that included all 15 elements, from the number of scale increments to the presence or absence of a display panel. New insights included the fact that the number of scale increments, shape of the instruments, and size of the cap had a weaker impact than other design factors, so it was decided that no matter what parameters were used, ideal instrumentation could be generated for the target group with these design factors. Therefore, the study selected the most commonly used conventions in the market for these factors. For twin gauges, for example, the speedometer was placed on the right and the tachometer on the left with a small cap. Gauge shape 2 was selected and a model was generated (Figure 8). As it was found that the three subjective words identified using text-mining tools (sporty, sharp, and youthful) could also be linked with parts of the gauge, the model was also able to reflect the text mining results. 


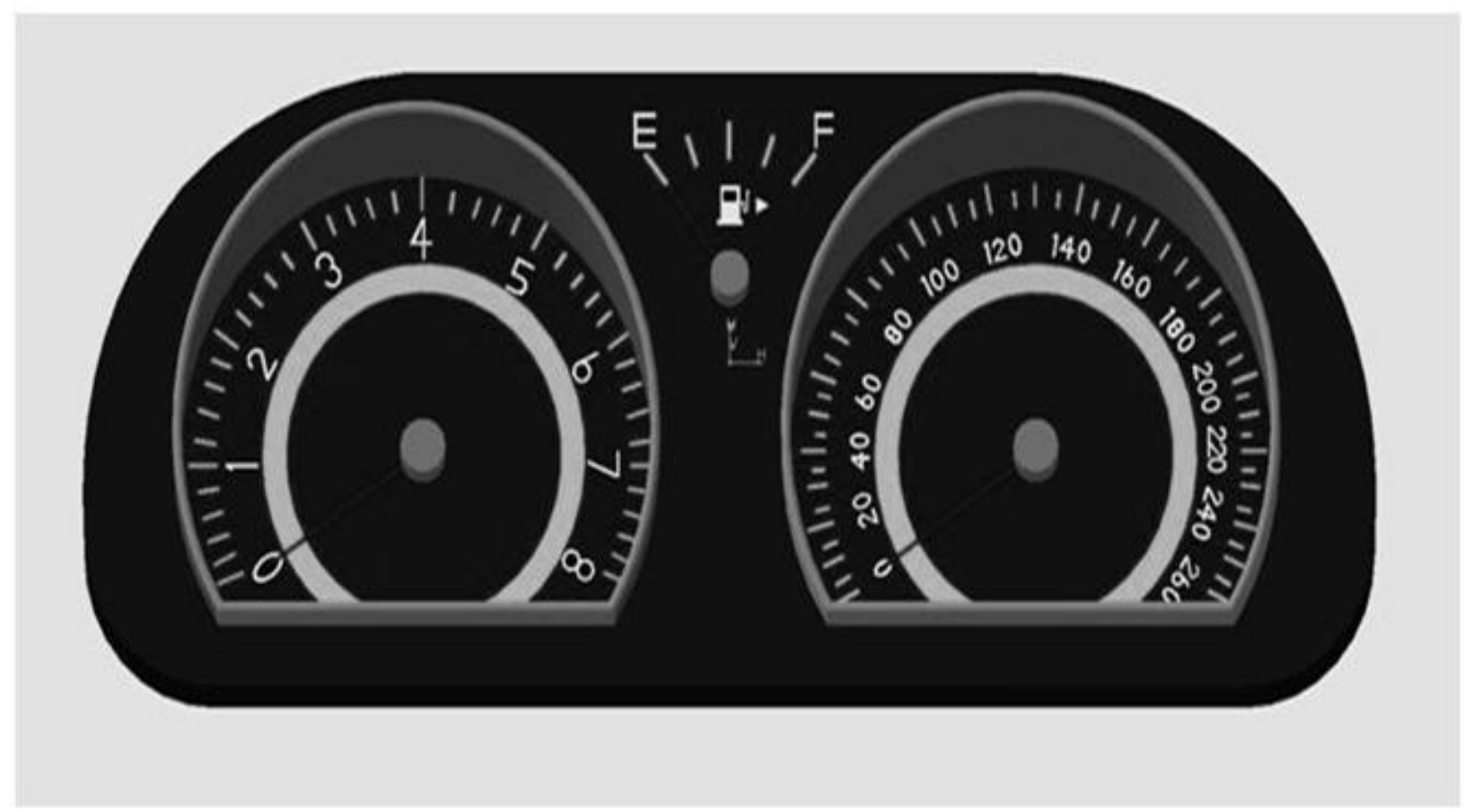

Figure 8: Auto Instrumentation Designed for Design-conscious Users

\section{Verifying the Effectiveness of the Design Approach Model}

The members of the design-conscious group were asked to evaluate the instrumentation design developed using CAD on a seven-point scale. The average scores were sporty (6.3), sharp (6.1), and youthful (6.4) - meaning that the design was well-received for each aspect and an instrumentation design that accurately achieved its aim, in terms of impression on the target group, was achieved. Next, in order to verify the effectiveness of the design approach model used in the study, interviews were conducted with instrumentation manufacturers. Feedback, such as "this could be used as a tool to support communication between designers and those in the production engineering departments" and "this would be useful as a way for designers to convince those in other departments of the value of their designs", was received and the effectiveness of the design approach model was thus verified.

\section{CONCLUSION}

This study focused on instrumentation design, qualifying previously undefined design aspects such as number of scale increments and needle shape. The research also aimed to measure the level of impact of these aspects on customers' subjective impressions, and the result was an Auto Instrumentation Designing Approach Model that accurately captures subjective customer preferences.

The design generated through the use of this model was able to express the desired qualities to target users, thus demonstrating its effectiveness.

\section{AUTHOR INFORMATION}

Koichiro Yazaki is a graduate student of the College of Science and Engineering at Aoyama Gakuin University. E-mail: c5611175@aoyama.jp. Corresponding author.

Haruki Tanitsu received his Bachelor of Engineering degree from the College of Science and Engineering at Aoyama Gakuin University. E-mail: k.snowman0126@gmail.com 
Hiroki Hayashi received his Bachelor of Engineering degree from the College of Science and Engineering at Aoyama Gakuin University. E-mail: 1001wanchan.rin@gmail.com

Kakuro Amasaka is a Professor in the College of Science and Engineering at Aoyama Gakuin University, Japan. $\mathrm{He}$ received his Ph.D. degree in Precision Mechanical and System Engineering, Statistics and Quality Control at Hiroshima University in 1997. Since joining Toyota Motor Corporation in 1968, He worked as a quality control consultant for many divisions, and the General Manager of the TQM Promotion Division (1998-2000). His specialty is New JIT, Science TQM, Science SQC, Numerical Simulation (CAE) and Customer Science. Now, He has been serving as the vice chairman of JSPM (2003-2007) and JOMSA (2008-2010), the director of JSQC (2001-2003), and the chairman of JOMSA (2011-). E-mail: Kakuro_amasaka@ise.aoyama.ac.jp. Corresponding author.

\section{REFERENCES}

1. Amasaka, K., Nagaya, A., and Matsubara, W., (1999), "Studies on Design SQC with the Application of Science SQC - Improvement of Business Process Method for Automotive Profile Design", Japanese Journal of Sensory Evaluations, Vol. 3, No. 1, pp. 21-29 (in Japanese).

2. Amasaka, K., (2005), "Constructing a Customer Science Application System "CS-CIANS" - Development of a Global Strategic Vehicle "Lexus" Utilizing New JIT", WSEAS Transactions on Business and Economics, Vol. 3, No. 2, pp.135-142.

3. Amasaka, K., (2006), "Applying TDS-DTM, Key to the Excellence Design "LEXUS"”, Proc. of the European Operations Management Association, No. 2, pp. 485-494.

4. $\quad$ Amasaka, K., (2007), "The Validity of "TDS-DTM": A Strategic Methodology of Merchandise Development of New JIT -Key to the Excellence Design "LEXUS"', International Business \& Economics Research, Vol. 6, No. 11, pp. 105-116.

5. Ando, T., Yamaji, M., and Amasaka, K., (2008), "A Study on Construction of Automobile Design Concept Support Methods - Visualization of Form and Customer Sensibility Utilizing Design CAD”, Nihon Hinshitsu Kanri Gakkai Dai 38 Kai Nenji Taikai Kenkyu Happyokai, pp. 177-180 (in Japanese).

6. Ando, T., Yamaji, M., and Amasaka, K., (2010), “A Study on Automobile Form Design Support Method "AFD-SM"”, Journal Of Business \& Economics Research, Vol. 8, No. 11, pp. 13-19.

7. Okabe, Y., Yamaji, M., and Amasaka, K., (2006), "Research on the Automobile Package Design Concept Support Methods "CS-APDM"”, Proc. of the $11^{\text {th }}$ Annual International Conference on Industrial Engineering-Theory, Application and Practice, pp. 268-273.

8. Shibata, H., Asai, T., Tanaka, K., Tatsubuchi, M., Ogata, S., and Nishihira, M., (2003), "Study of Automobile Meters from Universal Perspective - Efficiency of Ambient Metering Devices", DENSO Technical Review, Vol. 8, No.1, pp.66-72 (in Japanese).

9. Shimada, K., and Shinomori, K., (2006), (Graduation paper), The Influence of Color Variation of VehicleMounted Meter to Readability of Speed, Kochi University of Technology (Unpublished) (in Japanese).

10. Takebuchi, S., Asami, H., Nakamura, T., and Amasaka, K., (2010), "Creation of Automobile Exterior Color Design Approach Model "A-ACAM"', The 40th International Conference on Computers \& Industrial Engineering, Awaji Island, Japan, July, pp. 1-5 (CD-ROM).

11. Tanitsu, H., Hayashi, H., and Yazaki, K., (2011), (Graduation paper), Jidosha Keiki Design Approach Model ni kansuru Kenkyu Jyakunen Dansei no Kansei wo Toraeta Design Sosyutsu wo Rei Toshite , Aoyama Gakuin University (Unpublished) (in Japanese).

12. Yamamoto, S., Ogawa, Y., Mori, K., Nonaka, H., and Sanada, H., (2004), "Spiral-up Process by Face-toface Interview with Users for Car Meters Development", Journal of Society of Automotive Engineers of Japan, Vol. 58, No. 12, pp. 77-82 (in Japanese). 